\title{
Pip, a novel IRF family member, is a lymphoid-specific, PU.1-dependent transcriptional activator
}

\author{
Charles F. Eisenbeis, ${ }^{1}$ Harinder Singh, ${ }^{1,2}$ and Ursula Storb ${ }^{1,3}$ \\ ${ }^{1}$ Department of Molecular Genetics and Cell Biology, ${ }^{2}$ Howard Hughes Medical Institute, University of Chicago, Chicago, \\ Illinois 60637 USA
}

\begin{abstract}
The immunoglobulin light-chain gene enhancers $E_{\kappa 3^{\prime}}, E_{\lambda 2-4}$, and $E_{\lambda 3-1}$ contain a conserved cell type-specific composite element essential for their activities. This element binds a B cell-specific heterodimeric protein complex that consists of the Ets family member PU.1 and a second factor (NF-EM5), whose participation in the formation of the complex is dependent on the presence of DNA-bound PU.1. In this report we describe the cloning and characterization of Pip (PU.1 interaction partner), a lymphoid-specific protein that is most likely NF-EM5. As expected, the Pip protein binds the composite element only in the presence of PU.1; furthermore, the formation of this ternary complex is critically dependent on phosphorylation of PU.1 at serine-148. The Pip gene is expressed specifically in lymphoid tissues in both B- and T-cell lines. When coexpressed in NIH-3T3 cells, Pip and PU.1 function as mutually dependent transcription activators of the composite element. The amino-terminal DNA-binding domain of Pip exhibits a high degree of homology to the DNA-binding domains of members of the interferon regulatory factor (IRF) family, which includes IRF-1, IRF-2, ICSBP, and ISGF3 $\gamma$.
\end{abstract}

[Key Words: Pip protein; PU.1; lymphoid tissues; IRF family; transcriptional activator; immunoglobulin $\lambda$ genes]

Received March 7, 1995; revised version accepted April 25, 1995.

The expression of immunoglobulin genes, which encode the heavy- and light-chain subunits of the antibody molecule, is tightly regulated in a cell type- and developmental stage-specific fashion. Expression of these genes in B cells is controlled both at the level of transcription and recombination. Multiple cis-regulatory elements, promoters, and enhancers appear to confer proper developmental regulation of transcription (Calame and Eaton 1988; Sen and Baltimore 1989; Staudt and Lenardo 1991). Immunoglobulin gene transcriptional enhancers also play a critical role in regulating $V(D) J$ recombination (Ferrier et al. 1990; Engler et al. 1991; Takeda et al. 1993). Cell type-specific enhancers were first identified in the $\mathrm{J}-\mathrm{C}$ introns of both the heavy (Banerii et al. 1983; Gillies et al. 1983; Neuberger 1983) and $\kappa$ light chain (Queen and Baltimore 1983; Picard and Schaffner 1984) genes. More recently, additional enhancers have been identified $3^{\prime}$ of the constant region genes in both the heavy (Matthias and Baltimore 1993; Pettersson et al. 1990) and $k$ light chain (Meyer and Neuberger 1989) loci. The $\lambda$ lightchain gene locus, which is organizationally distinct (Storb et al. 1989), possesses two transcriptional enhancers, each located $3^{\prime}$ of a $\mathrm{J}_{\lambda}-\mathrm{C}_{\lambda}$ gene cluster (Hagman et al. 1990). These two enhancers, designated $E_{\lambda 2-4}$ and $E \lambda 3-1$,

${ }^{3}$ Corresponding author. are $>90 \%$ homologous, are thought to have arisen by an evolutionary gene duplication event, and presumably function in a similar manner.

We have demonstrated previously that the $E_{\lambda 2-4}$ enhancer contains two domains, $\lambda A$ and $\lambda B$, which are essential for enhancer activity; mutation or deletion of either domain completely destroys enhancer function $(\mathrm{Ru}-$ din and Storb 1992; Eisenbeis et al. 1993). Both $\lambda$ A and $\lambda B$, which appear to be unrelated, have been shown to bind $B$ cell-specific factors in nuclear extracts (Rudin and Storb 1992). The $\lambda B$ element consists of two juxtaposed but distinct transcription factor-binding sites (Eisenbeis et al. 1993). One site of the composite element is bound by PU.1, a member of the ETS family of transcription factors, that has been shown to be required for the development of lymphoid and myeloid lineages (Klemsz et al. 1990; Scott et al. 1994). The other site is likely bound by NF-EM5, a B cell-specific factor initially shown to form a ternary complex with PU.1 and a domain of the immunoglobulin $\mathrm{E}_{\kappa 3^{\prime}}$ enhancer (Pongubala et al. 1992). The $\lambda B$ and $\kappa 3^{\prime}$ domains are homologous composite elements. Both sites of the composite element are required for enhancer function (Judde and Max 1992; Pongunbala et al. 1992; Eisenbeis et al. 1993). Intriguingly, whereas PU.l can bind the composite element on its own, NFEM5 is unable to do so (Pongubala et al. 1992; Eisenbeis 
et al. 1993). NF-EM5 is recruited onto the DNA by a specific interaction with PU.1. This protein-protein interaction is critically dependent on phosphorylation of PU.1 at serine residue 148 (Pongubala et al. 1993).

In this report we describe the cloning and characterization of a novel gene, Pip (PU.1 interaction partner) that encodes a PU.1-interacting protein with the properties expected of NF-EM5. PU.1 and Pip represent mutually dependent activators of the $\lambda B$ and $\kappa 3^{\prime}$ enhancer elements.

\section{Results}

\section{Isolation of the Pip gene}

Of the many B-cell proteins that bind specifically to the $\lambda A$ and $\lambda B$ elements in vitro (Rudin and Storb 1992), only PU.1 represents a cloned trancription factor (Eisenbeis et al. 1993). In an effort to clone other factors that bind to the $\lambda B$ elements of the $E_{\lambda 2-4}$ enhancer, we generated a $\lambda g t 11$ cDNA expression library from poly $(A)^{+}$RNA extracted from $J 558 \mathrm{~L}$, a murine $\lambda 1$-producing myeloma cell line. We screened the library using an in situ filter-binding assay (Singh et al. 1988) and concatenated $\lambda B$ probes. A screen of $1.2 \times 10^{6}$ plaques identified three short clones (all $<800 \mathrm{bp}$ ). Sequence analysis confirmed that the three clones, designated $\lambda 13, \lambda 15$, and $\lambda 37$, contained extensively overlapping cDNA inserts that represented a portion of an incomplete open reading frame (ORF). The three clones were predicted to code for 134, 186, and 188 amino acids, respectively, with presumed DNA-binding activity.

To determine the DNA-binding characteristics of the cloned proteins, extracts were made from Escherichia coli lysogens harboring the $\lambda 13$ and $\lambda 15$ clones. These extracts were tested in electrophoretic mobility shift assays (EMSAs) for their ability to bind to the $\lambda B$ site (Fig. 1A). Although there is no $\lambda \mathrm{B}$-binding activity present in a $\lambda$ gt 11 control lysogen extract, the $\lambda 13$ extract contains a protein that binds the $\lambda B$ element, forming a shifted complex in the gel. A similar result was obtained with the $\lambda 15$ extract (not shown), confirming that these two phage clones contain cDNA inserts that code for a protein that binds the $\mathrm{AB}$ enhancer element in vitro.

\section{Mapping the DNA binding site for Pip}

To further define the binding site for the $\lambda 13$-encoded protein, we tested the ability of the $\lambda 13$ lysogen extract to bind a series of mutant $\lambda B$ probes in an EMSA (Fig. $1 B, C)$. Not only does the protein encoded by the $\lambda 13$ clone bind the wild-type $\lambda \mathrm{B}$ element, but it also binds, albeit less tightly, a $\lambda B$ element containing a 4-base alteration in the core of the PU.1-binding site $(\mathrm{Bm} 1$, Fig. $1 \mathrm{~B}, \mathrm{C})$. This protein is unable, however, to bind to probes containing mutations in the region $3^{\prime}$ of the PU.1-binding site $(\mathrm{Bm} 2$ and $\mathrm{Bm} 3$, Fig. $1 \mathrm{C})$ or to a shorter probe in which a portion of this $3^{\prime}$ region has been deleted (Ets, Fig. 1C). These results suggest that unlike PU.1, whose binding requires the AGGA in the Ets consensus se-
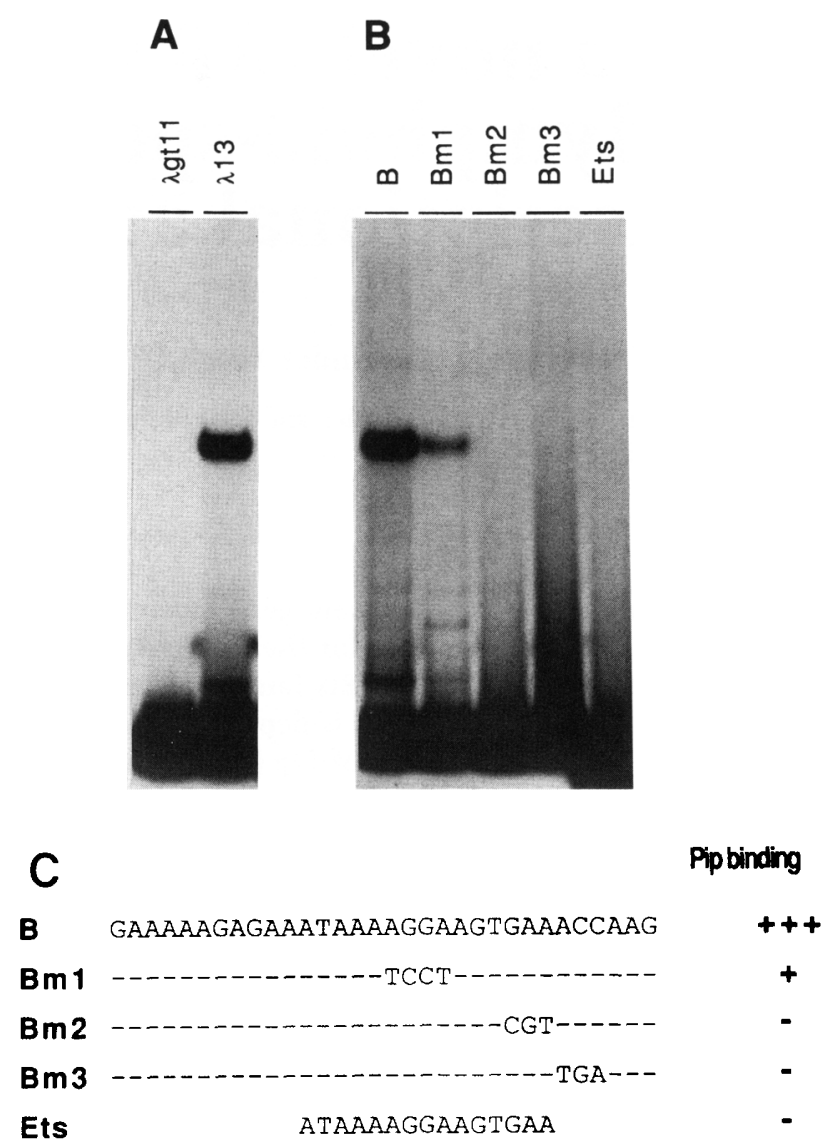

Figure 1. The $\lambda 13$-encoded protein binds $\lambda B$ specifically. $(A)$ Gel mobility shift assay using the $B$ probe and lysogen extracts from the parent vector ( $\lambda$ gt 11$)$ and the $\lambda 13$ clone. $(B)$ Gel mobility shift assay using the $\lambda 13$ lysogen extract and a series of $\lambda B$ probes. (C) Summary of the binding characteristics of the $\lambda 13$ clone. The sequences of the probes used in the gel shift analysis are shown. Dashes indicate residues that are identical to those at the analogous position in the $B$ probe. The ability of the $\lambda 13$-encoded protein Pip to bind to each probe is indicated.

quence core but not the $3^{\prime}$ sequence that is mutated in the $\mathrm{Bm} 2$ and $\mathrm{Bm} 3$ probes (Eisenbeis et al. 1993), the $\lambda 13$ protein binds the sequence $3^{\prime}$ of the PU.1 site.

To identify guanine residues involved in contacting the protein, a methylation interference assay was performed using the $\lambda 13$ lysogen extract and a methylated $\lambda B$ site probe. We analyzed the top (Fig. 2A) and bottom (Fig. 2B) strands of the $\lambda B$ probe; the results are summarized in Fig. $2 C$. On the top strand, methylation of the first guanine $3^{\prime}$ of the AGGA Ets consensus sequence core partially interferes with complex formation (shown as an open circle in Fig. $2 \mathrm{Cl}$. Methylation of the next guanine completely interferes with the ability of the $\lambda 13$ protein to bind the $\lambda B$ DNA /shown as a solid circle, Fig. $2 \mathrm{C})$, indicating that the $\lambda 13$ protein comes into close contact with the major groove of the DNA at this position. On the bottom strand only two adjacent guanines exist for analysis, and these lie $3^{\prime}$ of the PU.1-binding site. Methylation of either of these G's abolished $\lambda 13$ 
A

B
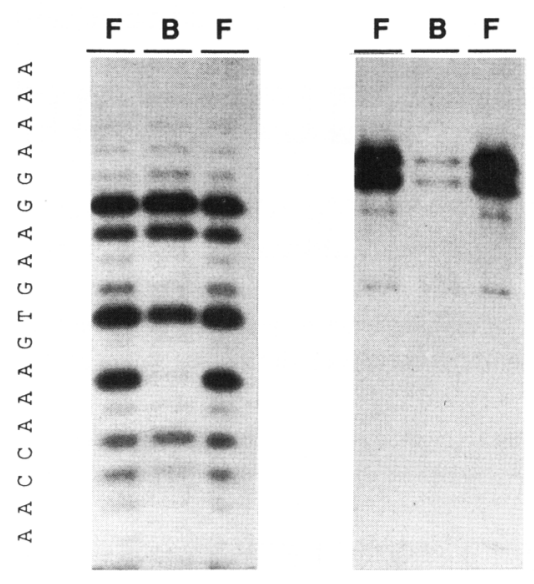

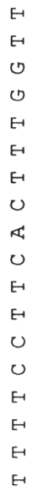

0

Pip

TAAAAGGAAGT GAAACCAAG ATTTTCCTTCACTITGGTTC

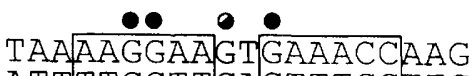
ATTTTCCTICACTTTGGTTC

\section{PU.1 TAAAAGGAAGTGAAACCAAG ATTTTCCTTCACTTTGGTTC}

Figure 2. Methylation interference analysis of the $\lambda 13$-encoded DNA-binding protein. Analysis of the upper $(A)$ and lower $(B)$ strands of the $B$ probe is shown. The $\lambda 13$ lysogen complex was isolated and analyzed. $(B)$ The complexed probe; $(F)$ the free probe recovered from the native gel. Corresponding sequences are shown for reference. $(C)$ Summary of the methylation interference analysis of the $\lambda 13$ complex in comparison to methylation interference results for the JB2 and PU.1 complexes (Eisenbeis et al. 1993). (Pip) The $\lambda 13$ complex. Sites of close contact between protein and DNA upon complex formation are indicated. (O) G residues whose methylation results in a complete loss of complex formation; (O) Residues whose methylation results in a substantial decrease in complex formation; $(O)$ residues whose methylation results in a modest decrease in complex formation. Protein binding sites are boxed.

protein binding, again suggesting that the $\lambda 13$ protein makes intimate contacts in the major groove at these two positions. The interference patterns delimit a minimal binding site for the $\lambda 13$ protein, which is adjacent to that determined previously for PU.l and is identical to that determined previously for the $3^{\prime}$-binding factor in the JB2 complex (Fig. 2C, Eisenbeis et al. 1993).

These binding site experiments demonstrate that the protein encoded by the $\lambda 13 \mathrm{cDNA}$ insert is capable of binding the $\lambda \mathrm{B}$ element at a site adjacent to the PU.1binding site and may therefore be a component of the JB2 complex described previously (Eisenbeis et al. 1993), which contains a factor (NF-EM5) that binds this se- quence. Interestingly, in EMSAs with J558L nuclear extract, we have not observed a binding activity that interacts with this site in the absence of simultaneously bound PU.1. These observations raised the possibility that whereas the truncated cloned protein could bind the $\lambda B$ element on its own, the full-length native molecule requires PU.1 for interaction with DNA.

\section{Isolating a complete Pip ORF}

To investigate the possibility of isolating a complete ORF, we screened the same J558L cDNA library with the $\lambda 13 \mathrm{cDNA}$ insert as a probe to obtain the complete cDNA sequence. A screen of $1 \times 10^{6}$ plaques identified $\sim 200$ clones containing inserts with homology to $\lambda 13$. Twenty of these were purified, and the four clones with the largest cDNA inserts were subcloned for sequencing. The longest of the clones, $\lambda 13.9$, had an insert of $1783 \mathrm{bp}$ (sequence submitted to GenBank), which contained a 64bp 5'-untranslated region (UTR), a long ORF of 1353 bp (65-1417), and a 365-bp 3' UTR. Because no poly(A) addition signal was found, this is unlikely to be the complete 3' UTR. The deduced ORF codes for a protein of 450 amino acids with a predicted molecular mass of 51.5 $\mathrm{kD}$. We have named this protein Pip (see below). All of the sequenced clones (including the short $\lambda 13, \lambda 15$, and $\lambda 37$ clones) share nearly identical $5^{\prime}$ ends. Thus, we believe that the $5^{\prime}$ end of the sequence is at or near the cap site. The sequence surrounding the putative initiator methionine is consistent with the loosely defined consensus sequence for eukaryotic translational initiation (Kozak 1987). In addition, the 64 bp of 5' UTR contains two translational stops in-frame with the coding sequence, suggesting that this is the true start of the ORF. It should be noted, however, that a second methionine occurs as the fourteenth amino acid in this sequence (Fig. 3A), and we have not ruled out the possibility that this may be an alternative translational start.

The shortest of the original clones, $\lambda 13$, codes for the first 134 amino acids of the Pip protein. Because this clone was identified by its ability to bind specifically to the $\lambda \mathrm{B}$ element in vitro, it localizes the DNA-binding domain to the first 134 amino acids of the Pip protein. Interestingly, this portion of the Pip protein sequence exhibits a considerable degree of sequence homology to the DNA-binding domains of the interferon consensus sequence-binding protein (ICSBP; Driggers et al. 1990) and other, related members of the interferon regulatory factor family (IRF) (Fig. 3A). In addition, Pip shares a series of small blocks of homology with ICSBP at similar positions in the carboxy-terminal half of each protein (Fig. 3B).

The amino-terminal half of the Pip protein is highly hydrophilic and is separated from the carboxy-terminal half by a potential PEST domain (a region rich in proline, glutamate, serine, and threonine residues whose presence in intracellular proteins correlates with a short halflife; Rogers et al. 1986). This 31-amino-acid domain (208-238) contains $45 \% \mathrm{P}, \mathrm{E}, \mathrm{S}$, and $\mathrm{T}$ and is flanked by basic amino acids. The region of the Pip protein that 


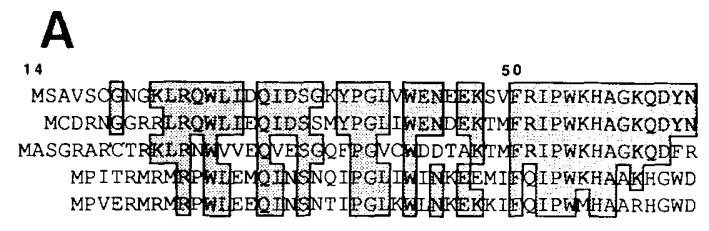

100

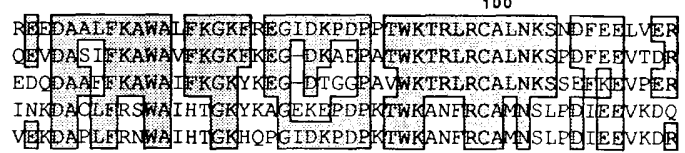

150

SOLD ISDPYKVYRIVPEGAKKAA ROL TLDD TQMAMGHPYPMTAPYGSLPA SQIDISSFP YKVYRIVPE--EECKCKLGVAPAGCMSEVP EMECGRSEIEE GRM EVAEPYKVYQLIP PIIVSGQPGTQKVP SKRQHSSVSSERKEEEDAMQ FRNKSSSAVRVYM MI PPLTRNQRARERKSKSSRDTKSKTKRKLCGDVSRDT SIKKGNNAF RVYRMI OLSERPS KAGKKPKTEKEERVKH I KQEPVE-SSLG

Figure 3. Comparison of Pip and related proteins. $(A)$ Comparison of Pip, ICSBP, ISGF3 $y$, IRF-1, and IRF-2 DNA-binding domains. The amino-terminal sequences are shown, starting with amino acid 14 of Pip and amino acid 1 of the other proteins. Numbering corresponds to the Pip sequence. Amino acids that are identical to the Pip sequence are boxed and shaded. $(B)$ Alignment of the protein sequences of Pip and ICSBP. Identical residues are boxed. Gaps that are introduced to allow alignment are arbitrarily placed.

contains this putative PEST domain is in general prolinerich (151-237, 20\% proline), representing a potential transcriptional activation domain (Mermod et al. 1989). In addition, there is a region in the carboxyl terminus of Pip that is rich in glutamine residues $(354-419,15 \%$ glutamine). Glutamine-rich domains have also been shown to function as transcriptional activation domains (Courey and Tjian 1988).

\section{Full-length Pip does not bind $\lambda B$ independently of PU.1}

To test the binding activity of the full-length Pip protein, we subcloned the complete ORF (from amino acid 2) and $218 \mathrm{bp}$ of $3^{\prime}$-untranslated sequence into pBSATG, which provides a strong initiator codon for in vitro translation (Baldwin et al. 1990). Recombinant Pip protein was produced and analyzed by EMSA for its ability to bind to the $\lambda B$ element (Fig. 4A,B) Although Pip was initially cloned by virtue of its ability to bind $\lambda B$, the full-length protein produced in vitro (Fig. 4B) does not display detectable binding activity in the EMSA (Fig. 4A). However, if recombinant PU.1 is supplied along with Pip, a complex migrating slower than the PU.1/ $\mathrm{AB}$ complex appears in the gel. This complex, which has an electrophoretic mobility identical to that of JB2, appears only when PU.1 and Pip are present in the reaction together and is de-

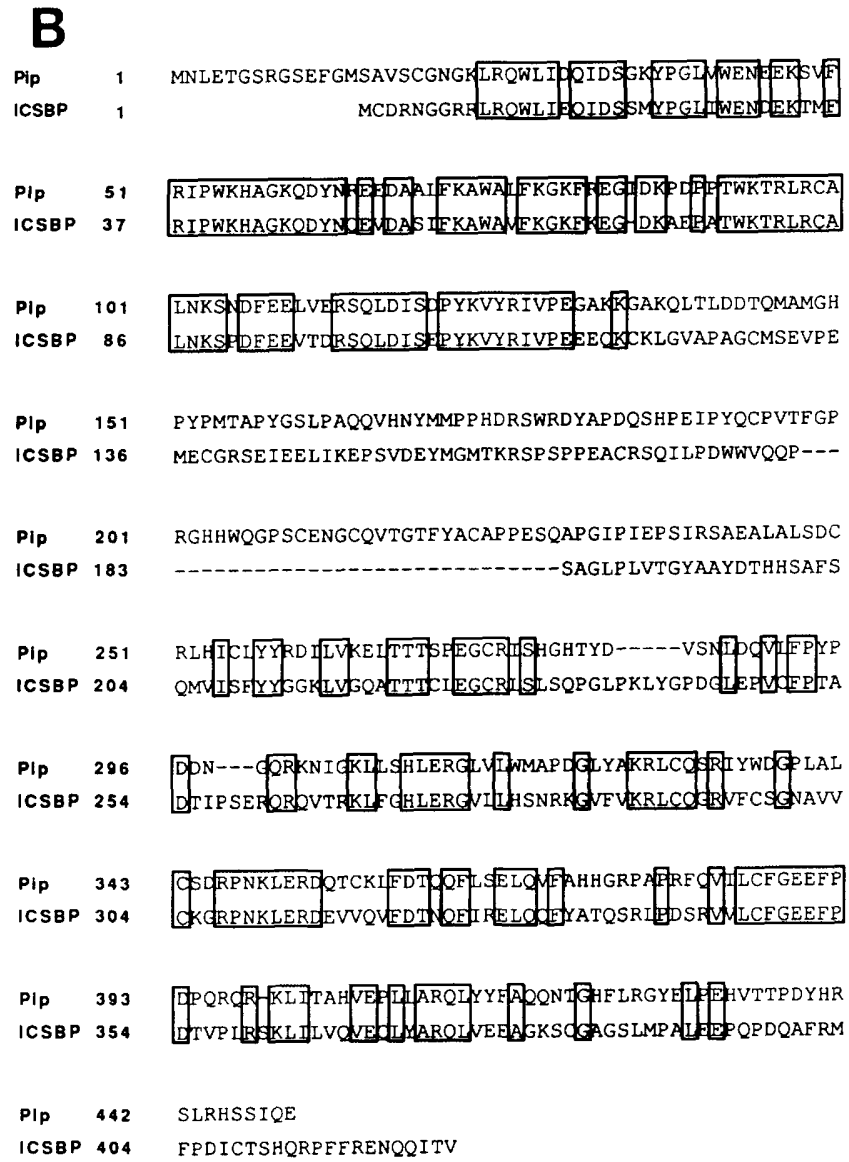

pendent on the presence of both the PU.1-binding site and the Pip-binding site, as mutation of either $(\mathrm{Bml}$ and $\mathrm{Bm} 2$, see Fig. $1 \mathrm{C}$ ) abolishes its formation. In addition, the formation of the Pip/PU.l complex is dependent on the presence of a serine residue at amino acid position 148 of the PU.1 protein, as mutation of this serine to alanine leads to a protein that can no longer recruit Pip to the $\lambda B$ site, even though its own DNA-binding ability is unaltered (Fig. 4A, S>A). This serine has been shown to be phosphorylated both in reticulocyte lysate-produced PU.1 and in PU.1 produced in vivo and, in its phosphorylated form, is required for the essential interaction between PU.1 and NF-EM5, which recruits NF-EM5 to its binding site on the $\kappa 3^{\prime}$ enhancer DNA (Pongubala et al. 1993). Therefore, phosphorylation of Ser-148 in PU.1 is also required for interaction with Pip.

The Pip protein binds specifically to the $\lambda B$ element, but only after interacting directly with a PU.1 protein whose intact binding site is nearby. This interaction requires serine at position 148 of the PU.1 protein and results in the formation of a ternary complex with a mobility identical to that of the previously described complex JB2. It is likely that Pip is the second component of the JB2 complex. It is the correct size and displays all of the unique DNA-binding characteristics that have been described for that factor. In addition, because the NFEM5 protein displays the same set of characteristics and 


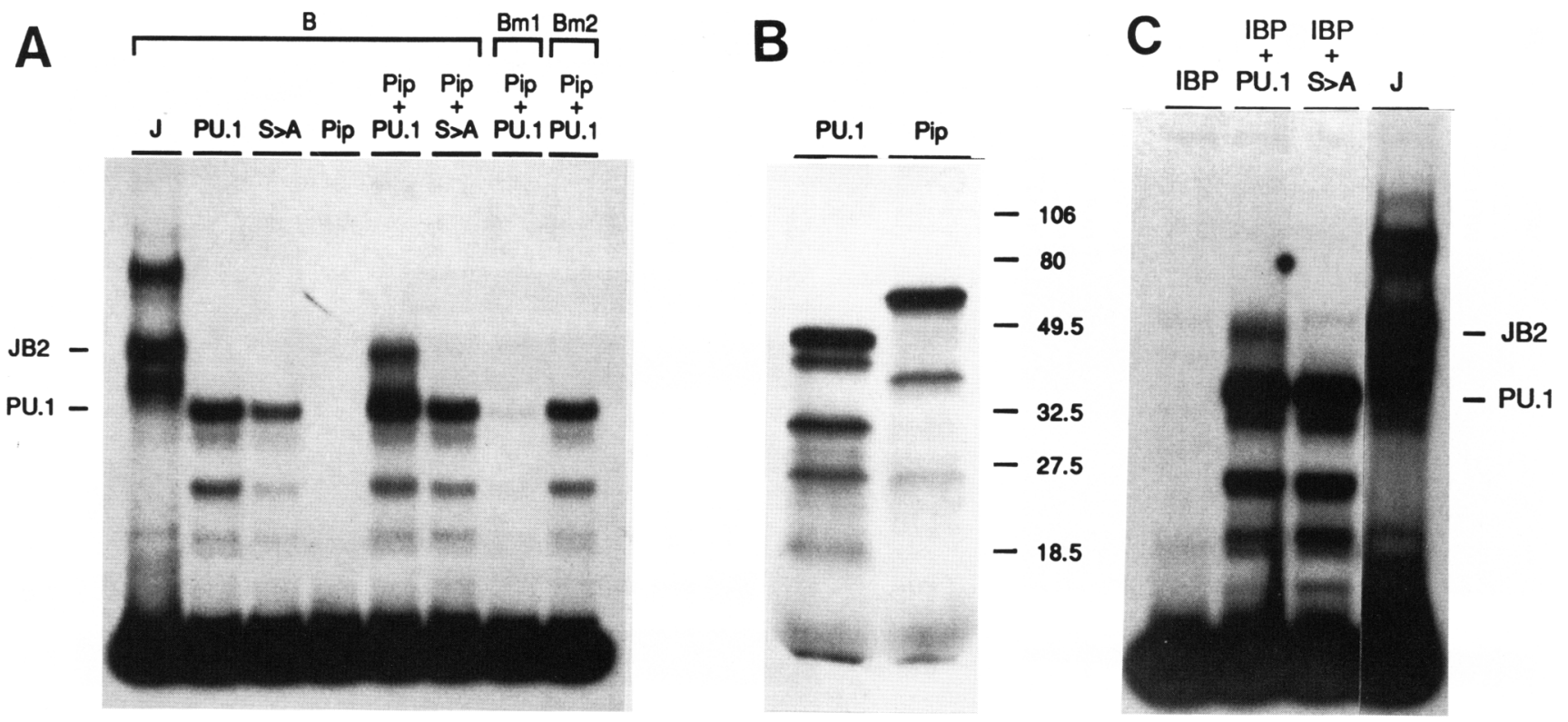

Figure 4. Binding characteristics of the Pip and ICSBP proteins. $(A \mid$ In a gel mobility shift assay, the full-length Pip protein binds to the B probe in a PU.1-dependent fashion. (B, Bml, and Bm2) Probes used in the assay. (J) J558L nuclear extract; (PU.1, S $>A$, and Pip) recombinant proteins. $(B)$ SDS-PAGE analysis of $\left[{ }^{35} \mathrm{~S} \mid\right.$ methionine-labeled recombinant proteins. Protein size markers are indicated. $(C)$ ICSBP interacts with PU.1 to form a ternary complex on the B probe. A gel mobility shift assay using the B probe and recombinant ICSBP and PU.1 proteins is shown. (IBP) Recombinant ICSBP protein. The mobility of the PU.1 and JB2 complexes is indicated.

participates with PU. 1 to form a $\lambda B$ complex with a mobility identical to that of JB2, it is likely that Pip and NF-EM5 are the same protein.

\section{ICSBP binds $\lambda B$ in conjunction with PU.1}

Because ICSBP is the protein related most closely to Pip with a nearly identical DNA-binding domain, we tested its ability to bind the $\lambda B$ element in the gel shift assay. ICSBP protein produced in the reticulocyte lysate system was unable to bind $\lambda B$ independently but was able to interact with PU.1 to form a complex that has a mobility identical to that of the Pip/PU.1 and JB2 complexes. (The size of the ICSBP protein produced in vitro is indistinguishable by SDS-PAGE from that of the Pip protein; C.F. Eisenbeis, unpubl.). The formation of the ICSBP/ PU.1 complex is also dependent on the presence of serine at position 148 of the PU.1 protein (Fig. 4C). Thus, ICSBP and Pip are identical in terms of their size and DNAbinding characteristics. Experiments with anti-ICSBP antibodies, however, indicate that ICSBP is not a major component of the JB2 complex (C.F. Eisenbeis, unpubl.). This suggests that ICSBP is not NF-EM5.

\section{The expression of Pip mRNA is tissue restricted}

To determine the pattern of Pip gene expression, we performed Northern blot analysis and ribonuclease protection assays (RPAs) on a variety of RNAs from murine tissues and cultured cell lines. Northern blot analysis of polyA ${ }^{+}$RNA from cultured murine cell lines (Fig. 5A) reveals that a $5-\mathrm{kb}$ message is present in all of the B-cell lines examined (J558L, WEHI 231, and lipopolysaccharide (LPS)-stimulated $70 \mathrm{Z} / 3$ ), but not in an erythroid line [myeloid erythroleukemia (MEL)]. An additional, abundant message of $2.5 \mathrm{~kb}$ and a less abundant message of $1.5 \mathrm{~kb}$ are present only in $\mathrm{J} 558 \mathrm{~L}$, a myeloma line that expresses $\lambda 1$ light chains. The significance of these additional transcripts is unclear at the present time. Clearly, the complete Pip message is much longer $(5 \mathrm{~kb})$ than the largest cDNA clone that we have obtained 1.8 $\mathrm{kb})$. Because numerous cDNA clones have a common 5' end, the Pip message appears to contain a long 3' UTR.

Analysis of total RNA from cultured murine cell lines reveals a similar pattern of expression (Fig. 5B): A 5-kb message is present in all B-cell lines analyzed, whereas additional 2.5- and 1.5-kb messages are present in the myeloma lines only (J558L, S194, and MOPC315). No Pip message was detectable by Northern blotting in EL4 (a T-cell lymphoma) or NIH-3T3 (a fibroblast) cell lines.

To achieve greater sensitivity, further analysis of Pip gene expression was performed using an RPA. The Pip riboprobe used in this assay is 400 nucleotides in length, 350 of which will be protected by specific hybridization to Pip mRNA. A mouse $\beta$-actin probe was employed to control for RNA loading. Analysis of tissue RNAs shows that the Pip gene is expressed in murine spleen, thymus, and bone marrow but not liver, kidney, brain, or testes (Fig. 5C). Analysis of cultured cell line RNAs confirms that while expression of Pip RNA is greatest in the three myelomas, there is expression of the Pip gene in all B-cell types tested. The Pip message is also present, al- 

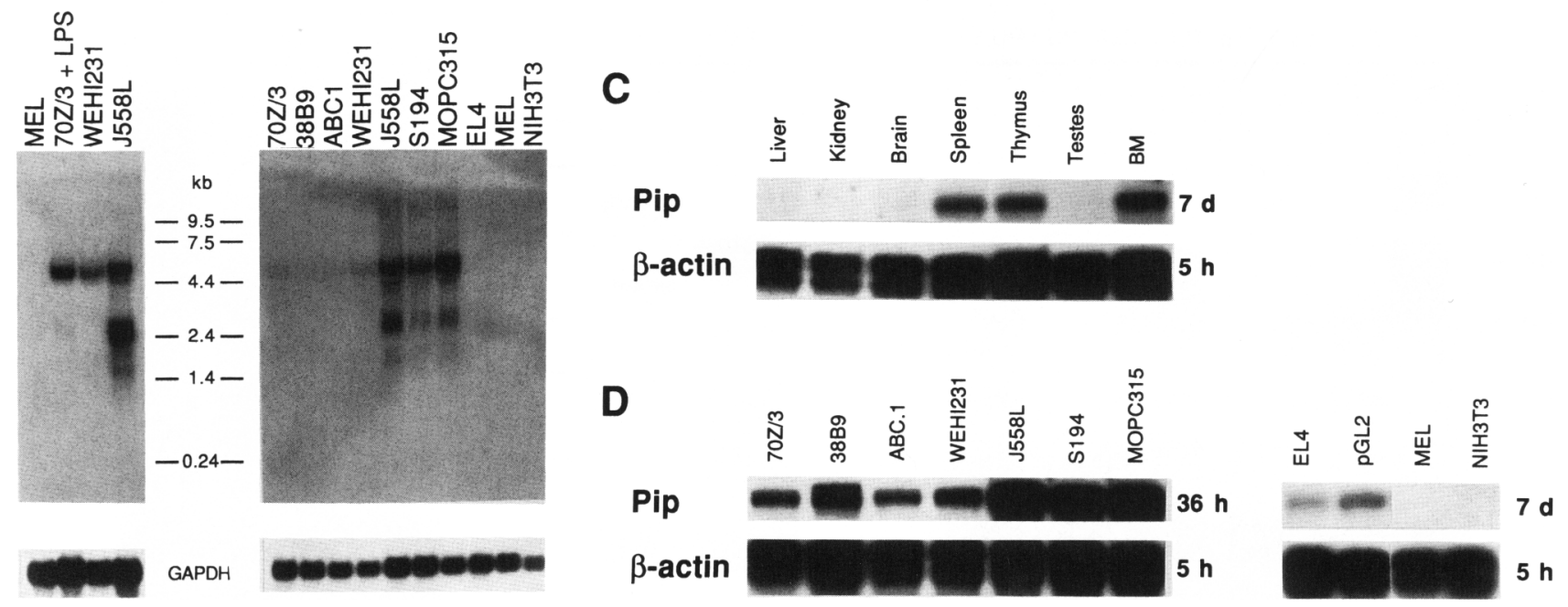

Figure 5. Analysis of the expression of Pip mRNA. A Northern blot analysis of $5 \mu \mathrm{g}$ of polyA ${ }^{+}$RNA $|A|$ and $10 \mu g$ of total RNA $|B|$ from cultured cell lines is shown. Blots were probed with a $679 \cdot \mathrm{bp} N \mathrm{col}$ fragment corresponding to the carboxy-terminal half of the Pip-coding sequence. Blots were rehybridized with a GAPDH probe to control for differences in sample loading. RNA size markers are indicated. An RPA of $5 \mu \mathrm{g}$ of total RNA from tissues $(C)$ and cultured cell lines $(D)$ is shown. A $\beta$-actin riboprobe was included in the RPA to control for RNA quantity. The time of exposure of each set of samples is indicated.

beit at a much lower level than in any of the B-cell lines, in two T-cell lines, EL4 and PGL2 (Fig. 5D). There is no detectable expression of Pip RNA in MEL or NIH-3T3 (Fig 5D). Preliminary evidence also suggests that the Pip gene is not expressed in macrophage lines (A. Brass, unpubl.).

The Pip gene appears to be expressed exclusively in lymphoid cells. In addition, it appears to be expressed at a higher level in B cells than in T cells. The comparable levels of expression in the spleen and thymus could either be attributable to high levels of Pip RNA in thymocytes or, more likely, contaminating B cells in the tissue preparation (the thymus RNA sample had large amounts of $k$ RNA|. Because PU.1 is restricted in its expression to the B-cell and macrophage lineages, the PU.1/Pip complex will only form in B cells, the only cell type in which the expression of both genes appears to overlap. Thus, this complex may play a critical role in determining the B-cell specificity of the $\lambda$ and $\kappa 3^{\prime}$ enhancers.

\section{In conjunction with PU.1, Pip functions as a transcriptional activator}

We have reported here that Pip and PU.1 interact to form a complex on the $\lambda B$ element of the $E_{\lambda 2-4}$ enhancer. We had shown previously that when multimerized, this element was sufficient to drive transcription of a reporter gene transiently transfected into the terminally differentiated B-cell line, J558L (Eisenbeis et al. 1993). To determine whether the complex formed by Pip and PU.1 has transcriptional activating potential, we cotransfected expression plasmids containing PU.1 and Pip cDNAs into
NIH-3T3 cells (which express neither protein) along with a chloramphenicol acetyltransferase (CAT) reporter construct containing the thymidine kinase (TK) promoter and a tetramer array of $\lambda B$ sites (Fig. 6). The $\lambda B$ sites function as cell type-specific activation elements, as they promote transcription in $5558 \mathrm{~L} \mathrm{~B}$ cells but not in NIH-3T3 fibroblasts. Whereas expression of Pip or PU.1 alone had no effect on CAT expression, the simultaneous expression of Pip and PU.1 in 3T3 cells was sufficient to drive transcription of the reporter. Coexpression of Pip with the S148A mutant of PU.1 did not lead to an appreciable increase in CAT expression, suggesting that the direct interaction between these two proteins is important in vivo as well as in vitro. These results suggest that Pip acts as a transcriptional activator in conjunction with PU.l, which is required for Pip to bind to the $\lambda B$ element. Interestingly, PU.1, which has been shown by others to be a transcriptional activator (Klemsz et al. 1990), cannot activate transcription alone through the $\lambda B$ tetramer.

\section{Discussion}

We have identified Pip, a novel transcription factor, which interacts with the Ets protein, PU.1, to form an activating complex on the $\lambda B$ motif of the $E_{\lambda 2-4}$ enhancer. Pip does not bind $\lambda B$ autonomously but relies on DNAbound PU.1 to facilitate its binding to this DNA element. Pip is restricted in its expression to $B$ and $T$ cells; because PU.1 is not expressed in the T lineage, the Pip/ PU.1 complex is B cell specific and may thus be an important determinant of the B cell specificity of the mu- 
Pip, a PU.1-dependent transcriptional activator

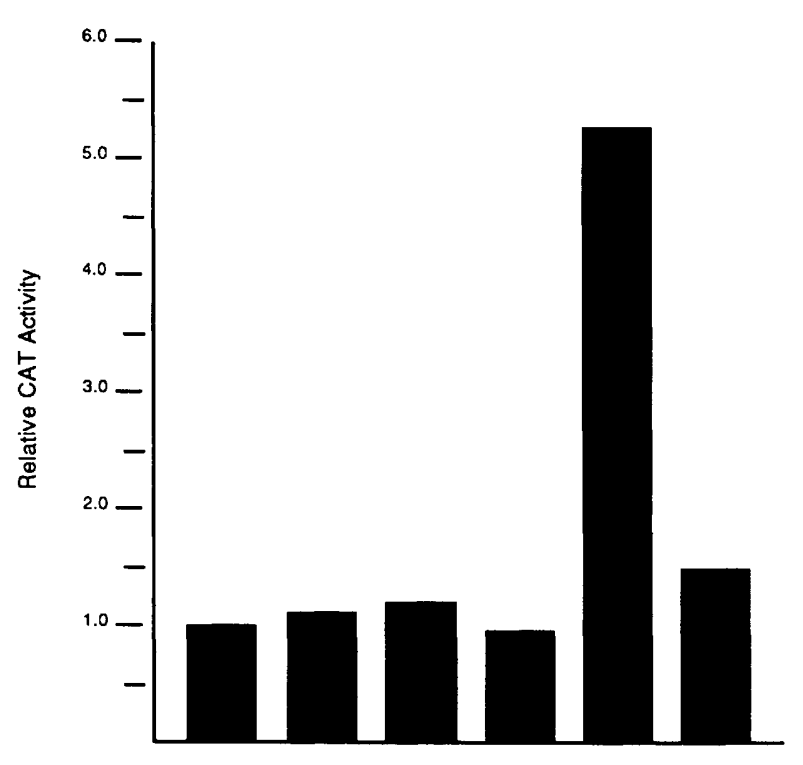

$\begin{array}{lllllll}\text { B४TKCAT } & + & + & + & + & + & + \\ \text { PU.1/CMV } & - & + & - & - & + & - \\ \text { S148A/CMV } & - & - & + & - & - & + \\ \text { PIP/CMV } & - & - & - & + & + & +\end{array}$

Figure 6. Functional analysis of the Pip protein. Ectopic expression of Pip and PU.1 in cultured NIH-3T3 fibroblasts with a CAT reporter gene whose expression is under the control of a tetramer of $\lambda B$ elements. PU.1, Pip, and PU.1 S148A cDNAs are cloned into a eukaryotic expression vector containing the CMV promoter and enhancer. The reporter is the B4TKCAT construct (Eisenbeis et al. 1993). The indicated constructs were transiently cotransfected into NIH-3T3 cells. After $46 \mathrm{hr}$, cells were harvested and extracts were analyzed for CAT activity. The results are reported as an average of at least three independent transfections. The activity of the reporter alone has been set at 1.0 .

rine immunloglobulin $\lambda$, as well as $\kappa 3^{\prime}$, enhancers. The Pip/PU.1 complex is identical in every respect to the NF-EM5/PU.1 and JB2 complexes described previously.

Pip is a novel member of the IRF family, particularly related to ICSBP

The amino-terminal DNA-binding domain of the Pip protein displays a strikingly high degree of homology to the DNA-binding domains of the IRF family, including IRF-1, IRF-2, ICSBP, and ISGF3y (Fig. 3 A). The Pip protein is $80 \%$ identical to ICSBP across this region (amino acids $24-130$ of Pip). In addition, Pip and ICSBP share many contiguous segments of homology in their carboxy-terminal halves (see Fig. 3B). The two proteins are $48 \%$ homologous over a 160 -amino-acid region of the Pip protein (Pip amino acids 254-413). Thus, Pip represents a new member of the IRF gene family that is related most closely to ICSBP.
The IRF-1, IRF-2, ICSBP, and ISGF3 $\gamma$ proteins are all transcription factors implicated in mediating transcriptional responses of cells to interferon stimulation (for review, see Williams 1991; Pellegrini and Schindler 1993). ISGF3 $y$ is one of the subunits of the multimeric transcription factor ISGF3 (Darnell et al. 1994) whose nuclear localization is regulated by interferon signaling. Whereas ISGF3 and IRF-1 function as activators of transcription (Fujita et al. 1989; Kessler et al. 1990), ICSBP and IRF-2 function as transcriptional repressors (Harada et al. 1989; Weisz et al. 1992; Nelson et al. 1993).

\section{DNA binding by Pip}

The Pip protein is able to bind specifically to sequences essential for the activities of the murine E $\lambda 2-4$ (this paper) and $E_{\kappa 3}$, (C.F. Eisenbeis and A. Brass, unpubl.) enhancers. In each case, Pip binding requires that PU.1 be bound at its adjacent binding site. We have shown that the Pip DNA-binding domain, itself, can bind to these sites independently, suggesting the presence of an inhibitory domain within Pip that prevents DNA binding by the full-length protein. We postulate that interaction with PU.1 alters the conformation of Pip to unmask its DNA-binding domain and allow it to interact with the $\lambda B$ sequence. The interaction between Pip and PU.1 is reminiscent of a similar interaction between the Ets family members Elk-1 and SAP-1, which interact with serum response factor (SRF) to form a ternary complex on the bipartite binding site of the serum response element (SRE) of the c-fos promoter (Hipskind et al. 1991; Dalton and Treisman 1992).

\section{Interaction between Pip and PU.1}

The binding of Pip to the $\lambda \mathrm{B}$ element is dependent on direct interaction between the Pip and PU.1 proteins and requires the presence of a serine residue at position 148 of the PU.1 protein. Phosphorylation of S148 occurs both in vivo and during translation of PU.1 in the reticulocyte lysate system and is required for the interaction between PU.1 and NF-EM5 (Pongubala et al. 1993). The fact that this phosphorylation is also required for the PU.1/Pip interaction further supports the contention that Pip is NF-EM5. This phosphorylation event could represent a regulated step in the control of immunoglobulin $\kappa$ and $\lambda$ light-chain gene expression. Interestingly, $\lambda B / P U .1$ can also form a trimolecular complex with ICSBP, which also requires phosphorylation of S148 of PU.1.

The carboxy-terminal region of the Pip protein, which appears to be required for interaction with PU.1 (C.F. Eisenbeis, unpubl.) is highly conserved in the ICSBP protein (Fig. 3B), representing a possible shared interaction domain. Recently, it has been discovered that the activity of ICSBP may also be regulated by association with related IRF family members IRF- 1 and IRF- 2 to form complexes that bind strongly to the $\alpha, \beta$ interferon (IFN$\alpha, \beta$ )-stimulated response element (ISRE) (Bovolenta et al. 1994). It will be interesting to determine whether Pip can also interact with IRF-1 and IRF-2. 


\section{Transcriptional activation by PU.1/Pip}

PU.1 has been shown to be a transcriptional activator (Klemsz et al. 1990) which possesses a transcriptional activation domain in the amino-terminal 75 amino acids (Hagemeier et al. 1993). However, when expressed alone in NIH-3T3 cells, PU.1 is incapable of stimulating the expression of a cotransfected CAT reporter whose transcription is driven by a tetramer of $\lambda B$ elements (Fig. 6). Perhaps the affinity of PU.1 for the $\lambda B$ site is lower than that for other sites, and an array of four sites is insufficient to achieve an activating potential. In this scenario, the Pip-dependent activation of the $\lambda B$ element by PU.1 could be attributable to cooperative binding (Fig. 4; Eisenbeis et al. 1993|. In addition, Pip may contain a transcriptional activation domain that enhances the activation potential of the complex.

The Pip protein contains a glutamine-rich domain at its carboxyl terminus and a proline-rich domain in the center of the protein sequence. Glutamine- and prolinerich sequences have been shown to function as transcriptioal activation domains (Courey and Tiian 1988; Mermod et al. 1989). In the Pip protein an 87-amino-acid region (151-237) contains $20 \%$ proline residues, and a 66-amino-acid region (354-419) contains $15 \%$ glutamine residues. Within these domains, the proline and glutamine residues are clustered, so that the P-rich domain consists of three P-rich modules (151-162, 33\% P; 172$200,24 \% \mathrm{P}, 225-237,38 \% \mathrm{P}$ ), and the Q-rich domain consists of two Q-rich modules $(354-369,25 \%$ Q, 395$419,20 \%$ Q). Recent reports suggest that some transcriptional activation domains have a modular structure composed of 10- to 20-amino-acid subdomains with little transactivational activity, which cooperate to form a highly functional activation domain when present in combination (Seipel et al. 1992; Sutherland et al. 1992). In addition, analysis of Oct- 2 and the Fos:Jun heterodimer has demonstrated that different types of activation domains may exist within a single transcription factor and that these domains cooperate to provide a greater activation potential (Sutherland et al. 1992; Tanaka et al. 1994).

\section{The role of IFNs in immunoglobulin gene expression}

The relationship of Pip to ICSBP and the IRF family has interesting implications for the regulation of immunoglobulin light-chain gene expression. The IRF family members are regulated by extracellular actions of IFNs and the consequently activated signaling pathways. Whereas IFNs have been shown to play important roles in the regulation of the murine immune system / Sen and Lengyel 1992), it is not known at the present time whether the expression of Pip, like ICSBP, is regulated by IFNs.

It is intriguing that the $\lambda \mathrm{B}$ and $\kappa 3^{\prime}$ composite elements are highly related to the ISRE. The ISRE consensus sequence is A/GNGAAANNGAAACT (Darnell et al. 1994). This is identical to the $\lambda B$ site, except at the highlighted positions (Fig. 1C). The $\lambda B$ and $\kappa 3$ ' elements may therefore function as ISREs, and expression of $\kappa$ - and $\lambda$-genes may be positively regulated by IFN- $\alpha, \beta$ signaling.

IFN- $\gamma$, on the other hand, stimulates the expression of ICSBP, which is most closely related to Pip. ICSBP antagonizes activation by IRF- 1 and ISGF3. Because ICSBP can also interact with PU.1 it may be a negative regulator of the $\lambda$ and $\kappa 3^{\prime}$ enhancers.

The expression of immunoglobulin light-chain genes is regulated at several levels. In late pre-B cells, the $\kappa$ and $\lambda$ light-chain loci become accessible to the action of the $V(D) I$ recombinase (Doglio et al. 1994). Germ-line transcripts of $\kappa$ and $\lambda$ genes can be detected at the time of rearrangement and are presumed to precede the joining events. It is not known, however, how the activation of these loci is controlled. The proportion of rearranged $k$ genes greatly exceeds that of $\lambda$ genes, and this discrepancy may be attributable to differential activation of the two loci. $\kappa$ genes are under the control of the $k$-intron enhancer $\left(E_{\kappa i}\right)$ and the $\kappa 3^{\prime}$ enhancer $\left(E_{\kappa}{ }^{3}\right)$, and only the latter is dependent on PU.1-NF-EM5/Pip. At the time of $\kappa$-gene rearrrangement, only the intron enhancer appears to be active (Chen et al. 1994; Klug et al. 1994). The $\lambda$ locus, on the other hand, is regulated only by enhancers dependent on the PU.1-NF-EM5/Pip complex. Thus, it is conceivable that at the early stage of B-cell development when the $E_{\kappa i}$ is active, and $E_{\kappa 3}$, is inactive, the $\lambda$ enhancers are also inactive. This would allow preferential accessibility of the $\kappa$ locus to the $V(D) /$ recombinase, whereas $\lambda$ remains inaccessible. It will be interesting to determine the roles of Pip/ICSBP and their control by interferons in the differential expression of $\kappa$ and $\lambda$ genes.

\section{Materials and methods \\ igt11 library construction and screening}

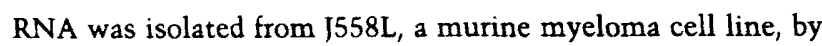
the guanidinium isothiocyanate method. Poly(A) ${ }^{+}$RNA was generated by two rounds of chromatography on an oligo(dT) cellulose column (Pharmacia). Using this poly $(\mathrm{A})^{+} \mathrm{RNA}$, a custom cDNA library was made in the $\lambda$ gt 11 vector by Stratagene. cDNA was synthesized by priming the reverse transcription reaction with both oligo(dT) and random primers. Primary plaques $\left(3.9 \times 10^{6}\right)$ were obtained, and $\sim 1 \times 10^{6}$ of these were used to amplify the library. By use of a tetramer of $\lambda B$ sites, $\sim 1.2 \times 10^{6}$ plaques were screened from the amplified library (Singh et al. 1988). The probe was isolated as a restriction fragment from a plasmid into which four directly repeated copies of the $\lambda B$ site had been cloned and labeled by filling in the overhanging ends with Klenow fragment in the presence of $100 \mu \mathrm{Ci}$ each of $\left[{ }^{32} \mathrm{P}\right] \mathrm{dATP}$ and $\left[{ }^{32} \mathrm{P}\right] \mathrm{dCTP}$. Putative positive clones were purified through at least five rounds of plaque purification. Specific binding affinity for the $\lambda \mathrm{B}$ probe was determined by probing each purified phage stock with a tetramer of $\lambda A$ sites in a similar in situ-binding assay. High titer stocks of recombinant phage were generated by the plate lysis method (Sambrook et al. 1989).

\section{Generation of lysogen extract}

$E$. coli lysogens harboring recombinant $\lambda g t l l$ phage were isolated as described (Singh 1991). After inducing for expression of 
$\beta$-gal fusion proteins, lysogenized cells were used to prepare soluble extracts for DNA-binding assays.

\section{In vitro transcription and translation}

Plasmids containing cDNA inserts were linearized $3^{\prime}$ of the coding sequence. Capped mRNA was synthesized by in vitro transcription of $1 \mu \mathrm{g}$ of linearized plasmid in the presence of 10 $\mathrm{mm} 7 \mathrm{mG}\left(5^{\prime}\right) \mathrm{ppp}\left(5^{\prime}\right) \mathrm{G}$ (New England Biolabs) and T3 or T7 RNA polymerase (Promega). After treatment with RNase-free DNase to remove the template, phenol extraction, ethanol precipitation, and resuspension in $20 \mu \mathrm{l}$ of water, $2 \mu \mathrm{l}$ of the RNA suspension was used to program a $50-\mu l$ rabbit reticulocyte lysate (Promega) in vitro translation reaction, which was incubated at $30^{\circ} \mathrm{C}$ for $1 \mathrm{hr}$. In some cases, parallel reactions were prepared in which the proteins were labeled by inclusion of $\left[{ }^{35} S \mid\right.$ methionine (NEN) in the reaction mix. When proteins were labeled with ${ }^{35} \mathrm{~S}$ they were analyzed by SDS-PAGE and autoradiography.

\section{EMSA and methylation interference}

EMSAs were performed as described (Singh et al. 1986; Eisenbeis et al. 1993/. Probes were generated by digestion of plasmid DNAs containing the sequence of interest and labeled by filling in the ends with Klenow in the presence of $\left[{ }^{32} \mathrm{P}\right] \mathrm{dCTP}$. Methylation interference analysis was performed as described (Baldwin 1988; Eisenbeis et al. 1993). Lysogen extract from the $\lambda 13$ cDNA clone was incubated with methylated $\lambda B$ site probe and electrophoresed on a $4 \%$ polyacrylamide gel to isolate free and complexed probe. Chemical cleavage products were electrophoresed on $5 \%$ polyacrylamide $/ 7 \mathrm{M}$ urea gels. Autoradiography was performed on dried gels.

\section{Subcloning and sequencing}

The cDNA inserts from the $\lambda g t 11$ clones were subcloned as NcoI-NdeI fragments into the EcoRV site of pBluescript II (SK + ) to generate $\lambda 13 \mathrm{~N} / \mathrm{N}, \lambda 15 \mathrm{~N} / \mathrm{N}, \lambda 37 \mathrm{~N} / \mathrm{N}, \lambda 37.5 \mathrm{~N} / \mathrm{N}$, and $\lambda 37.9 \mathrm{~N} / \mathrm{N}$. In the case of $\lambda 37.9$, which contains two $\mathrm{NcoI}$ sites within its coding sequence, the full-length insert was isolated from a partial NcoI-NdeI digest. In addition, the Pip-coding sequence from $\lambda 37.9 \mathrm{~N} / \mathrm{N}$ was subcloned as a MluI-Bcll fragment into the EcoRV site of pBluescript II ( $\mathrm{SK}+$ ) to generate $9(\mathrm{M} / \mathrm{B})$. The entire $\lambda 37.9 \mathrm{~N} / \mathrm{N}$ cDNA insert was sequenced completely on both strands by generation of a set of nested exonuclease III deletions from each end of the insert (Slatko et al. 1991), followed by sequencing with $\mathrm{T} 3$ and $\mathrm{T} 7$ primers, dideoxynucleotide chain terminators, and Sequenase enzyme. The Pip ORF was subcloned into the pBSATG vector to generate 9ATG by engineering a HindIII site just upstream of the second amino acid of the Pip protein by polymerase chain reaction (PCR) using the 9ATG primer (5'-GGGGAAGCTTAACTTGGAGACGGGCAG- $\left.3^{\prime}\right)$ in conjunction with the $T 7$ primer and $9(\mathrm{M} / \mathrm{B})$ as the template DNA. The Pip sequence was then isolated as a HindIII fragment, blunted by filling in with Klenow, and subcloned into SmaI-cut pBSATG (Baldwin et al. 1990). This construction places the Pip gene in the context of a strong translation initiation site and produces a protein in vitro that has the initial methionine and 8 amino acids provided by the vector and artificial restriction site, linked to the Pip ORF beginning with the second amino acid.

\section{Northern analysis}

Mouse tissue and cultured cell RNA was prepared by the guanidinium thiocyanate method. Poly $|A|+$ RNAs were fractionated on an oligo(dT)-cellulose column. For Northern analysis, $10 \mu \mathrm{g}$ of tissue RNA, $5 \mu \mathrm{g}$ of poly(A) ${ }^{+}$RNA, or $10 \mu \mathrm{g}$ of cultured cell RNA was electrophoresed on a $1 \%$ agarose/formaldehyde gel and blotted onto Hybond $\mathrm{N}$ nylon membrane (Amersham). Blots were hybridized for $\sim 16 \mathrm{hr}$ at $40^{\circ} \mathrm{C}$ in $50 \%$ formamide, $5 \times$ Denhardt's solution, $5 \times$ SSC, $0.1 \%$ SDS, $10 \mu \mathrm{g} / \mathrm{ml}$ of sonicated salmon sperm DNA, and $\sim 10^{6} \mathrm{cpm} / \mathrm{ml}$ probe. After washing at high stringency the blots were subjected to autoradiography.

\section{$R P A$}

RPAs were performed using the RPA II kit (Ambion). The Pip antisense riboprobe was generated by digestion of the $9(\mathrm{M} / \mathrm{B})$ Pip plasmid clone with NheI and transcription of the linearized plasmid in vitro using T7 RNA polymerase and $50 \mu \mathrm{Ci}$ of $\left.{ }^{32} \mathrm{P}\right] \mathrm{CTP}$. A $\beta$-actin control probe was synthesized in a similar manner using T3 RNA polymerase and the control plasmid DNA provided with the kit. Riboprobes were gel purified on $5 \%$ polyacrylamide/7 $\mathrm{M}$ urea gels before use. Hybridization reactions contained $10 \mu \mathrm{g}$ of tissue RNA or $5 \mu \mathrm{g}$ of cultured cell RNA and $5 \times 10^{4} \mathrm{cpm}$ of each riboprobe, and were incubated for $18 \mathrm{hr}$ at $45^{\circ} \mathrm{C}$ before digestion with RNase. Protected fragments were analyzed by electrophoresis on $5 \%$ polyacrylamide $/ 7 \mathrm{M}$ urea gels, followed by autoradiography with an intensifying screen at $-70^{\circ} \mathrm{C}$.

\section{Transient transfection and CAT assay}

The CAT reporter construct, $\mathrm{B}_{4}$ TKCAT has been described previously (Eisenbeis et al. 1993). To create Pip/CMV, PU.1/CMV, and S148A/CMV, the Pip, PU.1, and PU.1 S148A cDNAs were subcloned as HindIII-Xbal fragments into the HindIII and $\mathrm{Xbal}$ sites in the polylinker of pRc/CMV (Invitrogen), which places the cDNA inserts under the control of the CMV promoter. NIH $3 \mathrm{~T} 3$ cells were transfected by the DEAE-dextran protocol (Selden 1987) using a total of $25 \mu \mathrm{g}$ of DNA. Transfection involved $5 \mu \mathrm{g}$ of reporter construct and $10 \mu \mathrm{g}$ of the expression constructs, with the balance made up with empty expression vector. After $46 \mathrm{hr}$ at $37^{\circ} \mathrm{C}$, cell lysates were prepared and CAT assays performed using $160 \mu$ l of lysate as described previously (Eisenbeis et al. 1993). TLC plates were analyzed on a Molecular Dynamics PhosphorImager; the results shown here represent an average of at least three independent transfections.

\section{Acknowledgments}

We thank Richard Maki for the PU.1 and S148A cDNA clones, Keiko Ozato for the ICSBP cDNA clone and anti-ICSBP antibodies, Andrew Weng for RNA samples and the GAPDH probe fragment, and Robert Fisher, Kevin Fuller, and Cindy Go for RNA samples. In addition, we thank Abraham Brass for pointing out the relatedness of the $\lambda B$ site with an ISRE. This work was supported by grant IM-623 from the American Cancer Society to U.S. H.S. is supported by the Howard Hughes Medical Institute. C.F.E. was supported by National Institutes of Health predoctoral training grants GM07281 and FM07183, and a Medical Student Research Award from the Arthritis Foundation.

The publication costs of this article were defrayed in part by payment of page charges. This article must therefore be hereby marked "advertisement" in accordance with 18 USC section 1734 solely to indicate this fact.

\section{References}

Baldwin, A.S. 1988. Methylation interference assay for analysis of DNA-protein interactions. In Current protocols in molec- 
ular biology (ed. F.M. Ausubel, R. Brent, R.E. Kingston, D.D. Moore, J.G. Seidman, J.A. Smith, and K. Struhl), pp. 12.3.112.3.6. Greene Publishing Associates/Wiley-Interscience, New York.

Baldwin, A. Jr., K. LeClair, H. Singh, and P. Sharp. 1990. A large protein containing zinc finger domains binds to related sequence elements in the enhancers of the Class I major histocompatibility complex and kappa immunoglobulin genes. Mol. Cell. Biol. 10: 1406-1414.

Banerii, J., L. Olson, and W. Schaffner. 1983. A lymphocytespecific cellular enhancer is located downstream of the joining region in immunoglobulin heavy chain genes. Cell 33: $729-740$.

Bovolenta, C., P.H. Driggers, M.S.Marks, J.A. Medin, A.D.Politis, S.N. Vogel, D.E. Levy, K. Sakaguchi, E. Appella, J.E. Coligan, and K. Ozato. 1994. Molecular interactions between interferon consensus sequence binding protein and members of the interferon regulatory factor family. Proc. Natl. Acad. Sci. 91: 5046-5050.

Calame, K. and S. Eaton. 1988. Transcriptional controlling elements in the immunoglobulin and T cell receptor loci. Adv. Immunol. 43: 235-275.

Chen, Y., L. Wang, M. Huang, and N. Rosenberg. 1994. An active v- $a b l$ protein tyrosine kinase blocks immunoglobulin light chain gene rearrangement. Genes \& Dev. 8: 688-697.

Courey, A.J. and R. Tjian. 1988. Analysis of Sp1 in vivo reveals multiple transcriptional domains, including a novel glutamine-rich activation motif. Cell 55: 887-898.

Dalton, S. and R. Treisman. 1992. Characterization of SAP-1, a protein recruited by serum response factor to the $\mathrm{c}$-fos serum response element. Cell 68: 597-612.

Damell, J., I. Kerr, and G. Stark. 1994. Jak-STAT pathways and transcriptional activation in response to IFNs and other extracellular signaling proteins. Science 264: 1415-1421.

Doglio, L., J. Kim, G. Bozek, and U. Storb. 1994. Expression of $\lambda$ and $\kappa$ genes can occur in all $B$ cells and is initiated around the same pre-B-cell developmental stage. Dev. Immunol. 4: 1326.

Driggers, P.H., D.L. Ennist, S.L. Gleason, W.-H. Mak, M.S. Marks, B.-Z. Levi, J.R. Flanagan, E. Appella, and K. Ozato. 1990. An interferon $\gamma$-regulated protein that binds the interferon-inducible enhancer element of major histocompatibility complex class I genes. Proc. Natl. Acad. Sci. 87: 3743 3747.

Eisenbeis, C.F., H. Singh, and U. Storb. 1993. PU.1 is a component of a multiprotein complex which binds an essential site in the murine immunoglobulin lambda 2-4 enhancer. Mol. Cell. Biol. 13: 6452-6461.

Engler, P., P. Roth, J. Kim, and U. Storb. 1991. Factors affecting the rearrangement efficiency of an Ig test gene. I. Immunol. 146: 2826-2835.

Ferrier, P., B. Krippl, T. Blackwell, A. Furley, H. Suh, A. Winoto, W. Cook, L. Hood, F. Costantini, and F. Alt. 1990. Separate elements control DJ and VDJ rearrangement in a transgenic recombination substrate. EMBO I. 9: 117-125

Fujita, T., Y. Kimura, M. Miyamoto, E. L. Barsoumian, and T. Taniguchi. 1989. Induction of endogenous IFN- $\alpha$ and IFN- $\beta$ genes by a regulatory transcription factor, IRF-1. Nature 337: 270-272.

Gillies, S.D., S.L. Morrison, V.T. Oi, and S. Tonegawa. 1983. A tissue-specific transcription enhancer element is located in the major intron of a rearranged immunoglobulin heavy chain gene. Cell 33: 717-728.

Hagemeier, C., A.J. Bannister, S. Cook, and T. Kouzarides. 1993. The activation domain of transcription factor PU.l binds the retinoblastoma $(\mathrm{Rb})$ protein and the transcription factor
TFIID in vitro: $R b$ shows sequence similarity to TFIID and TFIIB. Proc. Natl. Acad. Sci. 90: 1580-1584.

Hagman, J., C.M. Rudin, D. Haasch, D. Chaplin, and U. Storb. 1990. A novel enhancer in the immunoglobulin $\lambda$ locus is duplicated and functionally independent of NFKB. Genes \& Dev. 4: 978-992.

Harada, H., T. Fujita, M. Miyamoto, Y. Kimura, M. Maruyama, A. Furia, T. Miyata, and T. Taniguchi. 1989. Structurally similar but functionally distinct factors, IRF-1 and IRF-2, bind to the same regulatory elements of IFN and IFN-inducible genes. Cell 58: 729-739.

Hipskind, R.A., V.N. Rao, C.G. Mueller, E.S. Reddy, and A. Nordheim. 1991. Ets-related protein Elk-1 is homologous to the c-fos regulatory factor p62TCF. Nature 354: 531-534.

Judde, J. and E. Max. 1992. Characterization of the human immunoglobulin kappa gene 3' enhancer: Functional importance of three motifs that demonstrate B-cell specific in vivo footprints. Mol. Cell. Biol. 12: 5206-5216.

Kessler, D.S., S.A. Veals, X.-Y. Fu, and D.E. Levy. 1990. IFN- $\alpha$ regulates nuclear translocation and DNA-binding affinity of ISGF3, a multimeric transcriptional activator. Genes \& Dev. 4: 1753-1765.

Klemsz, M.J., S.R. McKercher, A. Celada, C.V. Beveren, and R.A. Maki. 1990. The macrophage and B cell-specific transcription factor PU.l is related to the ets oncogene. Cell 61: 113-124.

Klug, C., S. Gerret, P. Shah, Y. Chen, N. Rice, N. Rosenberg, and H. Singh. 1994. The v- $a b l$ tyrosine kinase negatively regulates NF- $\mathrm{B} / \mathrm{Rel}$ factors and blocks $\kappa$ gene transcription in pre-B lymphocytes. Genes \& Dev. 8: 678-687.

Kozak, M. 1987. An analysis of 5'-noncoding sequences from 699 vertebrate messenger RNAs. Nucleic Acids Res. 15: 8125-8148.

Matthias, P. and D. Baltimore. 1993. The immunoglobulin heavy chain locus contains another B-cell-specific enhancer close to the $\alpha$ constant region. Mol. Cell. Biol. 13: 15471553.

Mermod, N., E.A. O'Neill, T.J. Kelly, and R. Tjian. 1989. The proline-rich transcriptional activator of CTF/NF-1 is distinct from the replication and DNA binding domain. Cell 58: 741-753.

Meyer, K.B. and M.S. Neuberger. 1989. The immunoglobulin $k$ locus contains a second, stronger B-cell-specific enhancer which is located downstream of the constant region. EMBO I. 8: 1959-1964.

Nelson, N., M.S. Marks, P.H. Driggers, and K. Ozato. 1993. Interferon consensus sequence-binding protein, a member of the interferon regulatory factor family, suppresses interferon-induced gene transcription. Mol. Cell. Biol. 13: 588599.

Neuberger, M.S. 1983. Expression and regulation of immunoglobulin heavy chain gene transfected into lymphoid cells. EMBO I. 2: 1373-1378.

Pellegrini, S. and C. Schindler. 1993. Early events in signalling by interferons. Trends Biol. Sci. 18: 338-342.

Pettersson, S., G.P. Cook, M. Brüggemann, G.T. Williams, and M.S. Neuberger. 1990. A second B cell-specific enhancer 3' of the immunoglobulin heavy-chain locus. Nature 344: 165168.

Picard, D. and W. Schaffner. 1984. A lymphocyte-specific enhancer in the mouse immunoglobulin $\kappa$ gene. Nature 307: 80-82.

Pongubala, J.M.R., C.Van Beveren, S. Nagulapalli, M.). Klemsz, S.R. McKercher, R. A. Maki, and M. L. Atchison. 1993. Effect of PU.1 phosphorylation on interaction with NF-EM5 and transcriptional activation. Science 259: 1622-1625. 
Pongubala, J.M.R., S. Nagulapalli, M.J. Klemsz, S.R. McKercher, R.A. Maki, and M.L. Atchison. 1992. PU.1 recruits a second nuclear factor to a site important for immunoglobulin $\kappa 3^{\prime}$ enhancer activity. Mol. Cell. Biol. 12: 368-378.

Queen, C. and D. Baltimore. 1983. Immunoglobulin gene transcription is activated by downstream sequence elements. Cell 33: 741-748.

Rogers, S., R. Wells, and M. Rechsteiner. 1986. Amino acid sequences common to rapidly degraded proteins: The PEST hypothesis. Science 234: 364-368.

Rudin, C.M. and U. Storb. 1992. Two conserved essential motifs of the murine immunoglobulin $\lambda$ enhancers bind B-cell-specific factors. Mol. Cell. Biol. 12: 309-320.

Sambrook, J., E. Fritsch, and T. Maniatis. 1989. Molecular cloning: A laboratory manual. Cold Spring Harbor Laboratory Press, New York

Scott, E., C. Simon, J. Anastasi, and H. Singh. 1994. Requirement of transcription factor PU.1 in the development of multiple hematopoietic lineages. Science 265: 1573-1577.

Seipel, K., O. Georgiev, and W. Schaffner. 1992. Different activation domains stimulate transcription from remote "enhancer" and proximal "promoter" positions. EMBO $/$. 11: 4961-4968.

Selden, R.F. 1987. Transfection using DEAE dextran. In Current protocols in molecular biology (ed. F.M. Ausubel, R. Brent, R.E. Kingston, D.D. Moore, J.G. Seidman, J.A. Smith, and K. Struhl), pp. 9.2.1-9.2.6. Greene Publishing Associates/ Wiley-Interscience, New York.

Sen, G.C. and P. Lengyel. 1992. The interferon system. I. Biol. Chem. 267: 5017-5020.

Sen, R. and D. Baltimore. 1989. Factors regulating immunoglobulin-gene transcription. In Immunoglobulin genes (ed. T. Honjo, F.W. Alt, and T.H. Rabbitts|, pp. 327-342. Academic Press, San Diego, CA.

Singh, H. 1991. Detection, purification, and characterization of cDNA clones encoding DNA-binding proteins. In Current protocols in molecular biology (ed. F.M. Ausubel, R. Brent, R.E. Kingston, D.D. Moore, J.G. Seidman, J.A. Smith, and K. Struhl), pp. 12.7.1-12.7.10. Greene Publishing Associates/ Wiley-Interscience, New York.

Singh, H., R. Sen, D. Baltimore, and A. P. Sharp. 1986. A nuclear factor that binds to a conserved sequence motif in transcriptional control elements of immunoglobulin genes. Nature 319: $154-158$.

Singh, H., J. Lebowitz, A. Baldwin, and P. Sharp. 1988. Molecular cloning of an enhancer binding protein: Isolation by screening of an expression library with a recognition site DNA. Cell 52: 415-423.

Slatko, B., P. Heinrich, B.T. Nixon, and D. Voytas. 1991. Constructing nested deletions for use in DNA sequencing. In Current protocols in molecular biology (ed. F.M. Ausubel, R. Brent, R.E. Kingston, D.D. Moore, J.G. Seidman, J.A. Smith, and K. Struhl), 7.2.1-7.2.20. Greene Publishing Associates/ Wiley-Interscience, New York.

Staudt, L.M. and M.J. Lenardo. 1991. Immunoglobulin gene transcription. Annu. Rev. Immunol. 9: 373-398.

Storb, U., D. Haasch, B. Arp, P. Sanchez, P. Cazenave, and J. Miller. 1989. Physical linkage of mouse $\lambda$ genes by pulsedfield gel electrophoresis suggests that the rearrangement process favors proximate target sequences. Mol. Cell. Biol. 9: $711-718$

Sutherland, J.A., A. Cook, A.J. Bannister, and T. Kouzarides. 1992. Conserved motifs in Fos and Jun define a new class of activation domain. Genes \& Dev. 6: 1810-1819.

Takeda, S., Y. Zou, H. Bluethman, D. Kitamura, U. Muller, and K. Rajewsky. 1993. Deletion of the immunoglobulin $\kappa$ intron enhancer abolishes $\mathrm{k}$ chain gene rearrangement in cis but not $\lambda$ chain gene rearrangement in trans. EMBO J. 12: 23292336.

Tanaka, M., W.M. Clouston, and W. Herr. 1994. The Oct-2 glutamine-rich and proline-rich activation domains can synergize with each other or duplicates of themselves to activate transcription. Mol. Cell. Biol. 14: 6046-6055.

Weisz, A., P. Marx, R. Sharf, E. Appella, P.H. Driggers, K. Ozato, and B.-Z. Levi. 1992. Human interferon consensus sequence binding protein is a negative regulator of enhancer elements common to interferon-inducible genes. J. Biol. Chem. 267: 25589-25596.

Williams, B.R.G. 1991. Transcriptional regulation of interferonstimulated genes. Eur. J. Biochem. 200: 1-11. 


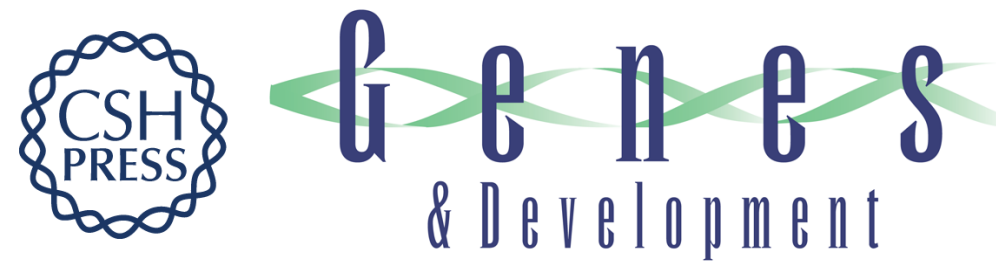

\section{Pip, a novel IRF family member, is a lymphoid-specific, PU.1-dependent transcriptional activator.}

C F Eisenbeis, $\mathrm{H}$ Singh and U Storb

Genes Dev. 1995, 9:

Access the most recent version at doi:10.1101/gad.9.11.1377

References This article cites 49 articles, 24 of which can be accessed free at:

http://genesdev.cshlp.org/content/9/11/1377.full.html\#ref-list-1

License

Email Alerting

Service

Receive free email alerts when new articles cite this article - sign up in the box at the top right corner of the article or click here.

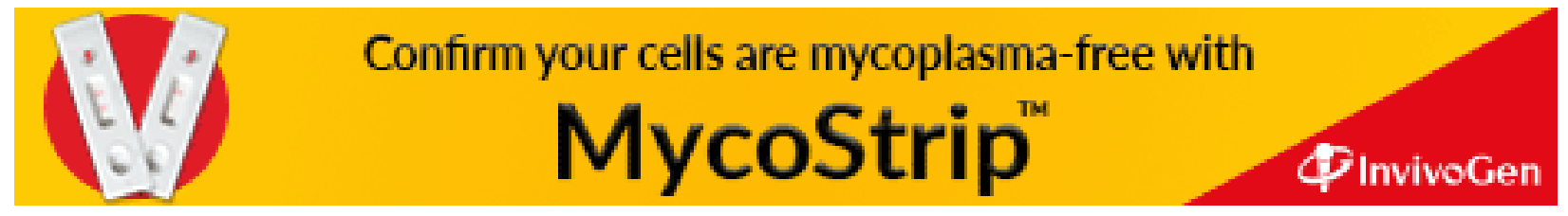

